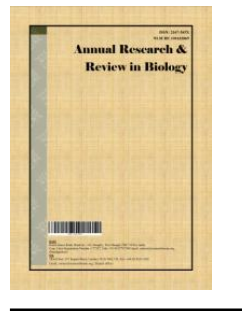

\title{
Production of Peanut Milk and Its Functional, Physiochemical, Nutritional and Sensory Characteristics
}

\author{
Azhari Siddeeg ${ }^{1 *}$, Zakaria A. Salih ${ }^{1,2}$, Al-Farga Ammar ${ }^{3}$, \\ Nahid Salah Mohammed Saeed ${ }^{1}$, Saad M. Howladar ${ }^{4}$ \\ and Fatima Omari Alzahrani ${ }^{5}$
}

${ }^{1}$ Faculty of Engineering and Technology, University of Gezira, Wad Medani, P.O. Box 20, Sudan. ${ }^{2}$ Research and Training Station, King Faisal University, Saudi Arabia. ${ }^{3}$ Department of Biochemistry, College of Sciences, University of Jeddah, Jeddah, Saudi Arabia. ${ }^{4}$ Department of Biology, College of Sciences, University of Jeddah, Jeddah, Saudi Arabia.

${ }^{5}$ Biology Department, Albaha University, Albaha, Saudí Arabia.

Authors' contributions

Authors AS and NSMS carried out the experimental work. Author ZAS helped the preparation of the manuscript and revision. Author AFA helped in the statistical analysis and the discussion of the results. Authors SMH and FOA revised the final paper.

Article Information

DOI: $10.9734 / A R R B / 2020 /$ 35i830262

Editor(s):

(1) Dr. Paola Angelini, University of Perugia, Italy. (2) Dr. Viduranga Y. Waisundara, Australian College of Business Technology, Sri Lanka.

Reviewers:

(1) Muhammad Faizal, Sriwijaya University, Indonesia. (2) Gabrielli Nunes Clímaco, University of Campinas, Brazil. (3) Tatianne Ferreira de Oliveira, Federal University of Goiás, Brazil. Complete Peer review History: http://www.sdiarticle4.com/review-history/59779

Original Research Article

Received 01 June 2020

Accepted 06 August 2020

Published 17 August 2020

\section{ABSTRACT}

This study was aimed to investigate the functional properties of peanut seeds, and physicochemical, nutritional and sensory analysis of processed peanut milk. Standard methods were used in this research to determine the functional properties and proximate composition, while minerals were determined by a flame photometer and colorimeter. Firstly, the functional proprieties of the whole and defatted kernel of peanut seeds were studied, and the best results were found in the defatted sample. Peanut milk samples were divided into four samples depends on the percentage of powder milk addition $(3,6,9$ and $12 \%)$ as well as the control sample without 
addition. The $\mathrm{pH}$, total soluble solids, viscosity, and density of samples were $(6.2-6.5,6-16 \%, 3-8$ $\mathrm{mPa} / \mathrm{s}$, and $1.01-1.05 \mathrm{~g} / \mathrm{cm}^{3}$, respectively), increased with the increasing of milk powder. About the proximate analysis, the highest values of ash, protein, fat, total carbohydrates $(0.8,6.3,6.3$, and $7.5 \%$, respectively) were found in the sample of $12 \%$ powder milk. Sodium, potassium, and calcium in the samples $(3,6,9$ and $12 \%$ ) were found in the range 38-58, 55-89, and $10-18 \mathrm{mg} / 100 \mathrm{~g}$, respectively. Sensory evaluation results revealed great acceptance for peanut milk made with $3 \%$ powder milk addition, while we're not found a significant difference in the color and taste of all samples and control. This study proved the possibility of using Sudanese peanut as a milk substitute which was found to be a good source of nutrients. This study suggested using peanut milk as a milk substitute, and in yogurt manufacture, future work should aim at studying optimum storage conditions and stable packaging requirements.

Keywords: Peanut seeds; functional properties; food processing; milk; organoleptic evaluation; minerals content.

\section{INTRODUCTION}

Peanut (Arachis hypogaea) is an annual herb who's chief, and the notable properties is the production of fruits underground. The many cultivars fall naturally into two distinct botanical groups depending upon differences between them in their branching habit [1]. Peanuts are rich in essential nutrients, In a $100 \mathrm{~g}$ serving, peanuts provide 570 calories and are an excellent source (defined as more than $20 \%$ of the Daily Value, DV) of several B vitamins, vitamin $E$, several dietary minerals, such as manganese (95\% DV), magnesium (52\% DV) and phosphorus (48\% DV), and dietary fiber (right table). They also contain about $25 \mathrm{~g}$ protein per $100 \mathrm{~g}$ serving, a higher proportion than in many tree nuts [2]. Peanut seeds grow into a green oval-leafed plant about 18 inches tall, which develops delicate yellow flowers around the lower portion of the plant. The flowers pollinate themselves and then lose their petals as the fertilized ovary begins to enlarge [3]. Some studies show that regular consumption of peanuts is associated with a lower risk of mortality specifically from certain diseases. Nevertheless, the research enterprises do not consent Cause Peanuts are rich in monounsaturated fats, the type of fat that is emphasized in the heart-healthy Mediterranean diet. Studies of diets with a special emphasis on peanuts have shown that this little legume is a big ally for a healthy heart. In one such randomized, double-blind, cross-over study involving 22 subjects, a high monounsaturated diet that emphasized peanuts and peanut butter decreased cardiovascular disease risk by an estimated $21 \%$ compared to the average American diet [4]. Protein ingredients must possess appropriate functional properties for food applications and consumer acceptability.
These are the essential physical and chemical properties which affect the behavior of protein in food systems during processing, manufacturing, storage and preparation, e.g., sorption, solubility, gelation, bureaucracy, ligand-binding, and film formation. These characteristics reproduce the conformation of the proteins, their interactions with other food constituents, and they are affected by processing actions and the environment. Because functional characteristics are affected by the structure, construction and shape of element proteins, systematic clarification of the physical possessions of component protein is expedient for understanding the mechanism of particular functional trains [5]. Meanwhile peanut is significant legume as its usages for numerous details in the world mainly Sudan which it uses daily as a food edible oil in our cooked food and as a butter in the meal. Cultivation of peanuts in the Sudan in many environment and production of edible oil has been accompanied with loose of crops contents, find alternatives to milk from nutrient source. Therefore, the main objective of this study was to produce peanut milk and its physiochemical characteristics, functional as well as its sensory analysis.

\section{MATERIALS AND METHODS}

\subsection{Materials, Tools and Equipment's}

Peanut was collected from a local market in Wad Medani City, Gezira State, Sudan, June, 2018, and was transported to the laboratory of food analysis department of Food Engineering and Technology, Faculty of Engineering and Technology, University of Gezira, Sudan. All other chemicals and reagents were of the highest grade commercially available. Equipment's 
(Oven, spectrophotometer, pH-meter, refractometer, centrifugation machine and Soxhlet) were used to conduct the experiments.

\subsection{Methods}

\subsubsection{Extraction oil by Soxhlet}

Hexane was heated to reflux, hexane vapour travels up a distillation arm, and floods into the chamber housing the thimble of solid. The condenser ensures that any solvent vapour cools, and drips back down into the chamber housing the peanuts. The chamber containing the peanut slowly fills with warm solvent. Some of the desired compounds dissolve in the warm solvent. When the Soxhlet chamber is almost full, the chamber is emptied by the syphon. The solvent is returned to the distillation flask. The thimble ensures that the rapid motion of the solvent does not transport any solid material to the still pot. This cycle takes 4 hours. During a cycle, a portion of the non-volatile compound dissolves in the solvent. At the end of the cycle, the desired compound was concentrated in the distillation flask. After extraction the solvent was removed, typically using a rotary evaporator, yielding the extracted oil [5].

\subsubsection{Functional properties}

The water absorption capacity (WAC) was estimated by the method of [5] with the modification described by [6]. $0.5 \mathrm{gm}$ of peanut flour added to $5 \mathrm{gm}$ distilled water was stirred in a centrifuge tube using a glass rod for 2 minutes at room temperature $\left(26^{\circ} \mathrm{C}\right)$. After 20 minutes equilibration, the suspension was centrifuged for 20 minutes at $440 \mathrm{rpm}$ at room temperature $\left(26^{\circ} \mathrm{C}\right)$. The freed water was decanted into a 10 $\mathrm{ml}$ graduated cylinder, and the volume was recorded. FAC of the samples was measured by a modified method of [5] 2 grams of the sample was treated with $20 \mathrm{ml}$ of refined peanut oil in a $15 \mathrm{ml}$ centrifuge tube. The suspension was stirred in a centrifuge tube using a glass rod for 2 minutes at room temperature $\left(26^{\circ} \mathrm{C}\right)$. The suspension was centrifuged for 20 minutes at $440 \mathrm{rpm}$ at room temperature $\left(26^{\circ} \mathrm{C}\right)$. The freed fat was decanted into a $10 \mathrm{ml}$ graduated cylinder, and the volume was recorded. BD was determined by the method of [7]. About 10 grams of material were placed in a $10 \mathrm{~mL}$ graduated cylinder and gently packed by tapping the cylinder on the bench (10) times to a reasonable height (approximately 5-8). The volume of the sample was recorded. Least gelation concentration of the sample was measured by the method of [8] with a slight modification. Appropriate sample suspensions of $(4,8,12$ and $16 \%$ ) were prepared in $100 \mathrm{ml}$ of distilled water. The test tubes containing these suspensions were then heated for one hour in a boiling water bath followed by rapid cooling under running cold tap water. The test tubes were further cooled for 3 hours at $\left(4^{\circ} \mathrm{C}\right)$. The least gelling concentration was determined as that concentration did not fall or slip when the test tube was inverted. Foam capacity (FC) was determined according to the method of [9]. Flour $(2 \mathrm{~g})$ was dispersed in 100 $\mathrm{ml}$ of distilled water and the contents transferred to a mixer blender whipped for $5 \mathrm{~min}$. At high speed for $5 \mathrm{~min}$. The contents, along with the foam, were poured into a $250 \mathrm{ml}$ measuring cylinder; the foam volume was recorded after 30 s. FC was expressed as percentage increase in volume. After $30 \mathrm{~min}$, the volume of foam was measured and expressed as follows: $\mathrm{FC}=$ Volume after whipping - Volume before whipping $\times 100$ Volume before whipping.

Emulsification Capacity was determined by the method of [1]. $1 \mathrm{~g}$ flour, added to $30 \mathrm{ml}$ peanut oil, these contents added to $60 \mathrm{ml}$ sodium hydroxide and the whole mixture in a blender at 9500 rpm for 30 minutes after that added another $30 \mathrm{ml}$ of oil to the mix and put the mix in centrifuge at speed 3000 rpm for 30 minutes.

\subsubsection{Processing of peanut milk}

Peanut milk was prepared by following the method of [10], with slight modifications. Sorted peanut seeds were cleaned and roasted at $100^{\circ} \mathrm{C}$ for $20 \mathrm{~min}$ in an oven. Roasting found to improve nutrient composition (protein, fibre and fat) and decrease the flavour of peanut. The seeds were then de-skinned and weighed before extracted oil. The kernels were then mixed with water in a ratio of $1: 4$ and transferred to a blender where they were blended for $5 \mathrm{~min}$ at medium speed. The slurry formed was filtered using a double-layered cheesecloth to prepare the peanut milk. After that Placed the peanut milk on the heater over medium heat until boil, after that added a pinch of salt, sugar and different concentration of powder milk along with additional vanilla for flavour and let it cool, after it has come to room temperature poured it in a pitcher.

\subsubsection{Proximate analysis}

Moisture determination was conducted using the [11]. Disposable aluminium weighing dishes, 
( $<50 \mathrm{~mm}$ diameter and $<40 \mathrm{~mm}$ deep) which had been numbered, dried in the oven for 30 minutes, cooled in a desiccator and weighed again were used. A two g sample was weighed out and repeated in triplicate. Using tongs, aluminium weighing dishes containing the samples were placed in an air-drying oven at $130^{\circ} \mathrm{C}$ for about one hour. The samples were removed and placed in a desiccator to cool for 30 minutes and reweighed. The ash content was determined according to the [11] using a muffle furnace. Four grams of the sample was weighed and repeated in triplicate into porcelain crucibles, which have been ignited, cooled in a desiccator and weighed and placed in a cool electric muffle furnace. The temperature was $540^{\circ} \mathrm{C}$ overnight for complete ashing. The ash crucibles were transferred directly into a desiccator, then cooled for 30 minutes and weighed immediately. Protein content was determined according to the Kjeldahl method described by [12]. Two grams of each sample were placed in digestion flask $(500 \mathrm{ml})$, KSO $\square$ was added to it. Then $25 \mathrm{ml}$ of concentrated sulfuric acid was added, and the content was heated at $35^{\circ} \mathrm{C}$ in a fume cupboard until a clear solution was obtained (2-3 hours) and left to cool before that antidumping granule was added. The digested samples were poured in a volumetric flask $(100 \mathrm{~mL})$ and diluted to 100 $\mathrm{mL}$ with distilled water. Five $\mathrm{mL}$ were distilled using $10 \mathrm{ml}$ of $40 \% \mathrm{NaOH} ; 25 \mathrm{ml}$ of boric acid with drops of methyl red were placed in a conical flask. Distillation of the reaction mixture liberated ammonia and reacted with boric acid, changing the colour from red to light greenish blue. Excess alkali was then titrated using $0.1 \mathrm{~N}$, hydrochloric acid until the colour changed to light purple. The titration reading was reported. The protein content was determined by multiplying the percentage nitrogen by empirical factor 6.36 . For fat content, a rapid volumetric method (Gerber method), as described by [13], was used for the determination of fat content of different samples. Ten $\mathrm{ml}$ of concentrated sulfuric acid was poured in a butyrometer tube. Then $10.94 \mathrm{ml}$ of mixed milk was added slowly at the sides, followed by $1.0 \mathrm{ml}$ of fat - free amyl alcohol, which was also added slowly at the sides, the tube was closed with special metal, and rubber stoppers and the content thoroughly and immediately centrifuged at $1100 \mathrm{rpm}$ for $10 \mathrm{~min}$. The tube was then transferred to a water bath at $65^{\circ} \mathrm{C}$ for $3 \mathrm{~min}$ for complete fat suspension. The percentage of fat was determined directly from butyrometer neck. The number of carbohydrates was calculated by difference. The values refer to "total carbohydrate by difference" that is, the sum of the figures for moisture ( $\mathrm{MC} \%)$, protein (PC \%), fat (FC \%), and ash (Ash \%) are subtracted from 100.

\subsubsection{Minerals}

According to AOAC Official Method, (2000), samples were dried and ashed at $525^{\circ} \mathrm{C}$ for 4 hours. The ash was dissolved in $(1 \mathrm{ml}$ hydrochloric acid $+3 \mathrm{ml}$ distilled water) and a few drops of nitric acid, brought to a final volume of $250 \mathrm{ml}$ with distilled water and filtered. Sodium, calcium and potassium, iron and phosphor were determined by flame atomic absorption spectroscopy according to [11].

\subsubsection{Reducing sugar content determination}

The reducing sugar content of samples and were estimated according to the Nelson- Somogyi, (2000) method. One $\mathrm{ml}$ of the sample was mixed with one part of solution $B$ and four parts of solution $A$. The mixture was boiled in water bath for 25-30 minutes, and then it was cooled under running tap water, and after that one $\mathrm{ml}$ of Nelson reagent was added. The optical density (O.D) of the samples has been read using spectrophotometer at wavelength $520 \mathrm{~nm} 10$.

\subsubsection{Physiochemical properties}

The $\mathrm{pH}$ of the peanut milk samples was estimated according to [11]. The $\mathrm{pH}$ of the samples was measured using a $\mathrm{pH}$ meter; the $\mathrm{pH}$ was determined by inserting the electrode of the $\mathrm{pH}$ meter in the sample then taking the result displayed on the $\mathrm{pH}$ meter. Total soluble solid content of peanut milk samples was estimated according to the [11]. The point from milk samples was taken and put in abbe refractometer and adjusted the point breaker and then read the focus. The viscosity of the samples was determined by the method of [14]. The spindle of the viscometer was inserted into the sample at the speed of $20 \mathrm{rmp}$, and the reading on the viscometer was taken after 3 minutes for each sample. The density of the samples was determined by the method of [15]. A $50 \mathrm{ml}$ bottle of density was washed and dried in the oven and weighted empty then filled by milk then dried and weighed again the difference between empty bottle weight and the weight of the bottle is full of milk equal the mass of milk.

\subsubsection{Sensory evaluation}

Semi-trained panellists were given a hedonic scale questionnaire to evaluate the peanut milk 
was evaluated through colour, texture, flavour and overall acceptability. They were scored on a scale of 9 points, in which (1: extremely bad, 2: very bad, 3: bad, 4: fairly bad, 5 : satisfactory, 6: fairly good, 7: good, 8: very good, 9: excellent). During the sensory evaluation, panellists were instructed to drink water or wash mouth after each evaluation. Sensory evaluation was done on the day in which bread was prepared.

\subsubsection{Statistical analysis}

The analysis of variance (ANOVA) was performed to examine the significant level in all parameters measured. (SPSS) The test was used to separate between the means. All analyses were performed in triplicate $(n=3)$. The level of significance was 0.005 [16].

\section{RESULTS AND DISCUSSION}

\subsection{Functional Properties of Peanut Kernel}

As shown in Table 1, water absorption capacity of defatted peanut kernel and hole seed were 2.0 and $1.0 \mathrm{~mL} / \mathrm{g}$, respectively, these results were found similar to that reported by [17], which was found water absorption capacity of peanut kernel $(2.0 \mathrm{~mL} / \mathrm{g})$ and lower than that reported by [18], which was found $(4.0 \mathrm{~mL} / \mathrm{g})$. Water and oil binding with proteins are very important in the food system because of their effects on the flavour and texture of foods. Generally, the protein subunit structure dissociates on heating or under extreme alkali conditions, and any possible factors that may affect these groups may cause changes in the water and oil absorption capacities. The WAC is an important functional property of flours due to swelling, and it affects the characteristics of body thickness and viscosity [17]. As also shown in Table 1, the oil absorption capacity of defatted peanut kernel and whole seed were found to be 1.0 and 1.75 $\mathrm{mL} / \mathrm{g}$, respectively. Oil absorption capacity was observed to be lower than that reported by [19], which was found $(2.93 \mathrm{~mL} / \mathrm{g})$ and in close agreement $(1.75 \mathrm{~mL} / \mathrm{g})$, which reported by [20]. As can be seen in Table 1, the bulk density of defatted peanut kernel and whole seed were 0.54 and $0.63 \mathrm{~g} / \mathrm{mL}$, respectively, these results were higher than that reported by Kaur and Singh (2006), which was found $(0.33 \mathrm{~g} / \mathrm{mL})$ and in agreement with that result reported by Kaur and Singh, (2005) which was found it $(0.63 \mathrm{~g} / \mathrm{mL})$ higher bulk density is desirable since it helps to reduce the paste thickness which is an important factor in convalescent and child feeding [21]. Bulk density is a property of powders defined as the mass of the many particles of the material divided by the total volume occupied. Gels may be defined by their ability to immobilise a liquid, their macromolecular structure, or their textural or rheological properties. The least gelation concentration for defatted peanut kernel and whole seed are shown in Table 1. Gelation values were 7.6 and $3.2 \%$; respectively, these results were similar to that reported by [22], which was recorded as 3.0 and $7.0 \%$ respectively for other varieties. It formed a weak gel at whole seed and strong gel at the defatted kernel. Variations in gelling properties may be ascribed to the ratios of different constituents, such as proteins, carbohydrates and lipids [20]. As illustrated in Table 1, foaming capacity of the defatted kernel and whole seed, were 1.0 and $4.0 \%$, respectively, the result of whole seed was similar to that reported by [17], which was found it as $4.0 \%$. Defatted peanut flours may not be suitable in the food system that requires foaming such as cake and ice cream. Foaming is an important characteristic feature of most proteins. Some food proteins can foam and maintain stable foams, depending on the type of protein, the degree of denaturation, $\mathrm{pH}$, temperature, and processing methods. The rheological and optical properties of thermally irreversible gels are the outcome of two events. First, a change in protein structure is needed that permits protein-protein interaction. As can also be seen in Table 1 the emulsifying properties of defatted kernel and hole seed were 18 and $10 \%$; respectively, these results were lower than that reported by [17], which was found $(20 \%)$ for defatted kernel and $(11.0 \%)$ for hole seed. The formation and stability of the emulsion are very important in food systems such as salad dressing. The presence and physiochemical properties of surfactants control the formation of stable emulsions. Proteins are preferred over low molecular weight surfactants for emulsification purposes in foods [22]. Emulsions form the basis of a huge range of food products, where those stabilised by proteins are of great interest. The interfacial properties of proteins have been extensively studied in the field of food colloid research. Emulsifying properties of proteins basically depend on two effects: a substantial decrease in the interfacial tension and the electrostatic, structural and mechanical energy barrier caused by the interfacial layer that opposes the destabilisation processes [17]. 
Table 1. Functional properties of defatted and whole seed of peanut

\begin{tabular}{lllllll}
\hline Samples & WAC $(\mathbf{m L} / \mathbf{g})$ & OAC $(\mathbf{m L} / \mathbf{g})$ & BD $(\mathbf{g} / \mathbf{m L})$ & GC (\%) & FC (\%) & EC (\%) \\
\hline Defatted & $2.0 \pm 1.40$ & $1.0 \pm 0.50$ & $0.54 \pm 0.40$ & $7.6 \pm 0.50$ & $0.01 \pm 0.02$ & $18 \pm 2.10$ \\
Whole seed & $1.0 \pm 0.70$ & $1.75 \pm 0.30$ & $0.63 \pm 0.20$ & $3.2 \pm 0.60$ & $4.0 \pm 0.20$ & $10 \pm 2.10$ \\
\hline \multicolumn{5}{c}{ WHC: Water absorption capacity; OAC: Oil absorption capacity; BD: Bulk density; GC: Gelation capacity; } \\
FC: Foaming capacity; EC: Emulsifying capacity
\end{tabular}

\subsection{The Chemical Composition of Peanut Milk}

The results of moisture, ash, protein, fat, carbohydrates and reducing sugar of processed peanut milk are illustrated in Table 2. As recorded in Table 2, the moisture content of peanut milk which has been added powder milk $3 \%, 6 \%, 9 \%, 12 \%$, were $88.9,87.2,85.4$ and 83.1, respectively, decreased with the increase of powder milk addition. These results are similar with that results were reported by [23], which was found the moisture content of soy milk at the range of $87.8-80 \%$ and were found to be lower than that reported by Nail, (1978), who reported $89.2 \%$. Also, this result was in agreement with the moisture content of raw milk was reported by [24], which was found to be $85 \%$. Control of moisture in products can be a vital part of the process of the product. There is a substantial amount of moisture in what seems to be dry matter. Ranging in products from cornflake cereals to washing powders, moisture can play an important role in the final quality of the product [25]. Data in Table 2, showed that the ash content of peanut milk $(3 \%, 6 \%, 9 \%$ and $12 \%$ ) were $0.4 \%, 0.5 \%, 0.6 \%$ and $0.8 \%$, respectively. The results were similar with results reported by [26] which was found the ash content of almond milk $0.6 \%$. Also, this result was similar (0.5) which reported by Liu and Chang, (2004) [27]. However, was higher than the result [28] 2\% and also higher than that result .3\% which reported by [29]. On the other hand, [29] reported that the ash content of soy milk was $0.9 \%$. Ashes are the solid remains of fires. Specifically, it refers to all non-aqueous, nongaseous residues that remain after something is burned. In analytical chemistry, to analyses the mineral and metal content of chemical samples, ash is the non-gaseous, non-liquid residue after complete combustion. Ashes as the end product of incomplete combustion will be mostly mineral, but usually still contain an amount of combustible organic or other oxidizable residues [30]. As shown in Table 2, The protein content of peanut milk $(3 \%, 6 \%, 9 \%$ and $12 \%$ ) was $1.7 \%, 3.1 \%, 5 \%$ and $6.3 \%$, respectively, this result indicates when added powder milk the rated of protein was increased. The ash result of peanut milk at $3 \%$ and $6 \%$ are lower than results obtained by [31] who found that the protein content of raw milk was $4.94 \%$, but near to the result of peanut milk when we added powder milk $9 \%$. However, it is higher than that obtained by [32].3.38\%, and similar with results reported by, which was found protein content of soy milk in the range $3.8-6 \%$. Food texture can be improved by enzyme-mediated covalent cross-linking of different food components, such as proteins and carbohydrates. Cross-linking changes the biological and immunological properties of proteins and may change the sensitising potential of food allergens [33]. The fat content of peanut milk (3\%, 6\%, 9\% and 12\%) were shown in Table 2, were $1 \%, 3.6 \%, 6.9 \%$ and 7.5 , respectively. These results were higher than that reported by [34] which was found fat content of raw milk 2.7, but in close agreement with that reported by [35] who found fat content 3.7. The total carbohydrate of processed peanut milk in Table 2, and showed total carbohydrates content at powder milk addition 3\%,6\%, 9\% and $12 \%$ were $3.3 \%, 5.6 \%, 6.9 \%$ and $7.5 \%$, respectively. These results are lower than results reported by [36] which was found the total carbohydrate of soy milk $8.9 \%$, and agreement with that reported by [37] who found the total carbohydrate of almond milk 7.5.

\subsection{Reducing Sugars Content}

As shown in Table 2, there were significant differences between peanut milk samples; the reducing sugar content was $(7.95,10,77,15,85$ and 21.50), respectively. This result was similar to that reported by [38] which was found the reducing sugar of soy milk in the range 7-20. A reducing sugar is any sugar that is capable of acting as a reducing agent because it has a free aldehyde group or a free ketone group. The monosaccharides can be divided into two groups: the aldoses, which have an aldehyde group, and the ketoses, which have a ketone group. Ketoses must first tautomerize to aldoses before they can act as reducing sugars. 
Table 2. Proximate analysis of processed peanut milk

\begin{tabular}{lllllll}
\hline PMA (\%) & Moisture & Ash & Protein & Fat & CHO & Reducing sugar \\
\hline $3 \%$ & $88.9 \pm 1.20$ & $0.4 \pm 0.30$ & $1.7 \pm 0.20$ & $1.0 \pm 0.40$ & $3.3 \pm 0.50$ & $7.95 \pm 0.60$ \\
$6 \%$ & $87.2 \pm 0.70$ & $0.5 \pm 0.20$ & $3.1 \pm 0.60$ & $3.6 \pm 0.50$ & $5.6 \pm 0.80$ & $10.77 \pm 1.30$ \\
$9 \%$ & $85.4 \pm 1.40$ & $0.6 \pm 0.30$ & $5.0 \pm 0.40$ & $4.9 \pm 0.50$ & $6.9 \pm 0.80$ & $15.85 \pm 0.60$ \\
$12 \%$ & $83.1 \pm 1.30$ & $0.8 \pm 0.30$ & $6.3 \pm 0.40$ & $6.3 \pm 0.70$ & $7.5 \pm 1.30$ & $21.50 \pm 0.90$ \\
\hline
\end{tabular}

PMA: Powder milk addition; $\mathrm{CHO}$ : Total carbohydrates

\subsection{Physicochemical Properties Processed Peanut Milk}

The $\mathrm{pH}$ value of peanut milk $(3 \%, 6 \%, 9 \%$ and $12 \%$ ) were shown in Table 3 , and were $6.6,6.5$, 6.3 and 6.2 , respectively, there is no significantly different effect on the $\mathrm{pH}$ value. These results were in close agreement with results reported by [39] which was found the $\mathrm{pH}$ value of soymilk in the range $6-6,6$. On the other hand, [34] reported that the $\mathrm{pH}$ of raw milk $6.7 \%$. The total solid content of peanut milk which has been added powder milk $(3 \%, 6 \%, 9 \%, 12 \%)$ were shown in Table 3 were 6, 11, 12 and 16\%, respectively, these results were higher than that reported by [28], which was found total solid content of soy milk at the range of $6-13 \%$, and similar with result reported by [33], who found total solid content of cow milk $(11.0 \%)$. The viscosity value of peanut milk $(3 \%, 6 \%, 9 \%$, $12 \%$ ) were shown in Table 3 were 3, 4, 6 and 8 $\mathrm{mPa} / \mathrm{s}$, respectively, these results were lower than that reported by [40], which was found the viscosity of coconut milk in the range of $6-12$ $\mathrm{mPa} / \mathrm{s}$, but these results are in full agreement with those reported by [41]. Viscosity is a property of the fluid which opposes the relative motion between the two surfaces of the fluid that are moving at different velocities. In simple terms, viscosity means friction between the molecules of the fluid. When the fluid is forced through a tube, the particles which compose the fluid generally move more quickly near the tube's axis and more slowly near its walls; therefore some stress is needed to overcome the friction between particle layers to keep the fluid moving [40]. of Data in Table 3 showed that the density value of peanut milk $(3 \%, 6 \%, 9 \%, 12 \%)$ were $1.01,1.02$, 1.03 and $1.05 \mathrm{~g} / \mathrm{cm}^{3}$ respectively, the result was similar with result reported by [41]which was found the density of soy milk 1.05 and lower than that reported by [38] which was found the density of soy milk $1.09 \mathrm{~g} / \mathrm{cm}^{3}$. Similarly, hydrostatic weighing uses the displacement of water due to a submerged object to determine the density of the object.

\subsection{Minerals Contents of Processed Peanut Milk}

As shown in Table 4, the minerals content was determined. Sodium content of $3 \%, 6 \%, 9 \%$ and $12 \%$ samples, were $38,44,54$ and $58 \mathrm{mg} / 100 \mathrm{~g}$, respectively, while the potassium content were $55,72,82$ and $89 \mathrm{mg} / 100 \mathrm{~g}$, respectively, while the calcium content were $10,12,14,18$ $\mathrm{mg} / 100 \mathrm{~g}$. Minerals content is associated with the ash content [19]. The result of sodium is lower than that results reported by [42], which was found sodium content of soy milk $59 \mathrm{mg} / 100 \mathrm{~g}$. While potassium content was higher than that reported by Rutgers, (2006), which was found $92.0 \mathrm{mg} / 100 \mathrm{~g}$, and calcium content was lower than that reported by [29], which was found calcium content of almond milk $33.0 \mathrm{mg} / 100 \mathrm{~g}$ (Table 4).

\subsection{Sensory Evaluation of Peanut Milk}

Sensory scores of peanut milk with different concentrations of powder milk addition and powder milk (control) were presented in Table 5. The analysis of variance (ANOVA) of the data showed that the effect of peanut milk on sensory

Table 3. Physicochemical properties of processed peanut milk

\begin{tabular}{lllll}
\hline PMA (\%) & pH & TSS & Viscosity & Density \\
\hline $3 \%$ & $6.6 \pm 0.20$ & $6.0 \pm 0.70$ & $3.0 \pm 1.40$ & $1.01 \pm 0.10$ \\
$6 \%$ & $6.5 \pm 0.20$ & $11 \pm 0.70$ & $4.0 \pm 2.10$ & $1.02 \pm 0.30$ \\
$9 \%$ & $6.3 \pm 0.30$ & $14 \pm 0.70$ & $6.0 \pm 2.20$ & $1.03 \pm 0.20$ \\
$12 \%$ & $6.2 \pm 0.30$ & $16 \pm 0.70$ & $8.0 \pm 1.40$ & $1.05 \pm 0.20$ \\
\hline
\end{tabular}

PMA: Powder milk addition; TSS: Total soluble solid 
Table 4. Minerals content $(\mathrm{mg} / 100 \mathrm{~g})$ of processed peanut milk

\begin{tabular}{llll}
\hline PMA (\%) & Na & K & Ca \\
\hline $3 \%$ & $38.0 \pm 0.05$ & $55.0 \pm 0.02$ & $10.0 \pm 0.12$ \\
$6 \%$ & $44.0 \pm 0.09$ & $72.0 \pm 0.03$ & $12.0 \pm 0.09$ \\
$9 \%$ & $54.0 \pm 0.03$ & $82.0 \pm 0.09$ & $14.0 \pm 0.22$ \\
$12 \%$ & $58.0 \pm 0.01$ & $89.0 \pm 0.11$ & $18.0 \pm 0.31$ \\
\hline
\end{tabular}

Table 5. Sensory analysis of processed peanut milk

\begin{tabular}{lllllll}
\hline PMA & Colour & Taste & Texture & Appearance & Flavour & Overall acceptability \\
\hline $3 \%$ & $8.80^{\mathrm{a}}$ & $7.70^{\mathrm{a}}$ & $8.00^{\mathrm{a}}$ & $8.60^{\mathrm{a}}$ & $8.40^{\mathrm{b}}$ & $8.40^{\mathrm{a}}$ \\
$6 \%$ & $6.80^{\mathrm{a}}$ & $6.10^{\mathrm{a}}$ & $6.00^{\mathrm{a}}$ & $7.10^{\mathrm{a}}$ & $6.20^{\mathrm{a}}$ & $6.60^{\mathrm{a}}$ \\
$9 \%$ & $7.40^{\mathrm{a}}$ & $7.20^{\mathrm{a}}$ & $7.30^{\mathrm{a}}$ & $8.00^{\mathrm{ab}}$ & $7.30^{\mathrm{b}}$ & $7.60^{\mathrm{a}}$ \\
$12 \%$ & $6.80^{\mathrm{a}}$ & $7.20^{\mathrm{a}}$ & $6.60^{\mathrm{b}}$ & $7.40^{\mathrm{ab}}$ & $8.30^{\mathrm{a}}$ & $7.70^{\mathrm{ab}}$ \\
Control & $7.40^{\mathrm{a}}$ & $6.30^{\mathrm{a}}$ & $7.00^{\mathrm{a}}$ & $7.90^{\mathrm{a}}$ & $6.20^{\mathrm{a}}$ & $7.10^{\mathrm{a}}$ \\
\hline
\end{tabular}

PMA: Powder milk addition

properties was statistically significant $(p<0.05)$ for samples evaluated in this study. Sensory evaluation of peanut milk samples was undertaken with consideration of the most acceptable parameters colour, taste, texture, flavour, appearance and the overall acceptability was taken and used as a control. The sensory properties of powder milk (control) are presented in Table 5. All sensory scores colour, texture, flavour, taste, appearance and overall acceptability were significant. All sensory scores were rated as acceptable by the panel. According to the results in Table 5, powder milk (control) showed excellent attributes in comparison with other types of peanut milk. The sensory properties of peanut milk with powder milk 3\%, $9 \%$ were presented in Table 5 all sensory scores, colour, texture, flavour, and overall acceptability were significantly different among blend samples, except flavor, and for the sample $12 \%$ all sensory scores were rated as acceptable by the panel except texture and appearance. According to the results in Table 5 the sample of peanut milk $6 \%$ showed excellent attributes in comparison with other types of milk.

\section{CONCLUSION}

The present study confirms the possibility of producing milk from peanut. The manufactured milk was analysed chemically, physically and subjected to sensory analysis. Peanut milk sample with $3 \%$ powder milk received the highest consumer acceptability scores compared with others. A significant increase in physiochemical properties with addition powder milk compared to raw milk.

\section{COMPETING INTERESTS}

Authors have declared that no competing interests exist.

\section{REFERENCES}

1. Beuchat LR, Cherry JP, Quinn MR. Physicochemical properties of peanut flour as affected by proteolysis. J. Agricultural and Food Chemistry. 1975;23:616-620.

2. Bryant LA, Montecalvo JJR, Morey KS, Loy. Processing, functional and nutritional properties of okra seed products. J. Food Sci. 1988;53:810-816.

3. Halward Tracy, Stalker Tom, LaRue Elizabeth, Kochert Gary. Use of singleprimer DNA amplifications in genetic studies of peanut (Arachis hypogaea L.). Plant Molecular Biology. 1992;18(2):315325.

4. Oshodi AA, Ekperigin MM. Functional properties of peanut; 1989.

5. Lin AS, Dorisi E. Certain Functional properties of some milk substitute. J. Food Sci. 1974;39:368-390.

6. Quinn MR, Beuchat LR. Functional property changes are resulting from fungal fermentation of peanut flour. J. Food Sci. 1975;40:475.

7. Wang JC, Kinsella JE. Functional properties of alfalfa leaf protein: Foaming. J. Food Sci. 1976;41:498-501.

8. Coffman C, Garcia VV. Functional properties and amino acid content of protein isolate from mug bean flour. J. Food Tech. 1977;12:473-478. 
9. Lawhon JT, Cater CM, Mattil KF. A Comparative study of the whipping potential of an extract from several oilseed flours. J. Cereal Sci. Today 1972;17:240244.

10. Salunkhe DK, Kadam SS (1989). Handbook of World Food Legumes: Nutritional Chemistry, Processing Technology and Utilization. $1^{\text {st }}$ Ed., CRC Press. Inc., Boca Raton.

11. AOCC. International Approved Methods of Analysis, $11^{\text {th }}$ Ed. Methods 08-01.01, 4415.02A, and 46-13.01. Available online only. AACCl: St. Paul, MN, Association of Official Analytical Chemists. Arlington, VA, USA; 2000.

12. AOAC. 1999. Official methods of Analysis of the Association of Official Analytical Chemists, $15^{\text {th }}$ ed. (Helrich, K., Ed) Arlington, VA. Basha, S.M. and Pancholy, S.K.; 1982.

13. Onimawo IA, Asugo S. Effects of germination on the nutrient content and functional properties of pigeon pea flour. J. Food Science and Technology-Mysore. 2004;41(2):170-174.

14. Jianmei Yu MA, Ipek G. (2007). Extrusion parameters and consumer acceptability of a peanut based meat analogue.

15. AOAC. Official Methods of Analysis of the AOAC, $15^{\text {th }}$ ed. Methods 932.06, 925.09, 985.29, 923.03; 2005.

16. Gleick PH, ed. Water in Crisis: A Guide to the World's Freshwater Resources. Oxford University Press. Table 2.1 Water reserves on the earth. 1993;13.

17. Rutgers R. The Consistency of Starch-milk Puddings. II.--Influence of Cooking and Cooling Conditions etc. and Type of Starch. J. Sci. Food Agric. 2006;9(2):6977.

18. Kaur M, Sandhu KS, Singh N. Comparative study of the functional, thermal and pasting properties of peanut flours from different field pea (Pisum sativum L.) and pigeon pea (Cajanus cajan L.) cultivars. Food Chemistry. 2006;104: 259-267.

19. Mizubuti IY, Junior OB, Souza LWD, DaSilva RSDF, Ida El. Functional properties of pigeon pea (Cajanus cajan (L.) Mill sp) flour and protein concentrate. Archives Latinoamericanos De Nutrition. 2000;50(3):274-280.

20. Kaur M, Singh N. Studies on functional, thermal and pasting properties of flours from different chickpea (Cicer arietinum L.) cultivars. J. Food Chemistry. 2005;91(3): 403-411.

21. Padmashree TS, Vijayalakshmi L, Puttaraj S. Effect of traditional processing on the functional properties of cowpea (Vigna catjang) flour. J. Food Science and Tech. 1987;24:221-224.

22. Akintayo ET, Oshodi AA, Esuoso KO. Effect of $\mathrm{NaCl}$, ionic strength and $\mathrm{pH}$ on the foaming and gelation of pigeon pea (Cajanus cajan) protein concentrates. J. Food Chemistry. 1999;66:51-56.

23. Ikya DI, Gernah HE, Ojobo OK. Effect of cooking temperature on some quality characteristics of soy milk. Advance Journal of Food Science and Technology; 2013.

24. Sohail M. The microbiological quality of milk produced in the Balearic Islands. International Dairy Journal. 1983;5:69- 74.

25. Nail. Nutritional and quality assessment of soy milk blend institute of food science and technology, University of Agriculture, Faisalabad -Pakistan; 1978.

26. Gallier S, Gordon K, Singh H. Chemical and structural characterization of almond oil bodies and bovine milk fat globules. Food Chemistry. 2012;132(4):1996-2006.

27. Diarra Nor, Aisha Hbint I, Hasa. Almond milk production and study of quality characteristics, Faculty of Applied Science, University of Technology MARA; 2009.

28. Hasan, N. A. (2012). Almond milk production and study of quality characteristics. Journal of Academia, 2(1), 1-8.

29. Agurbiade SO, Sharwie MH, Olanlokun JO. Evaluation of some nutritional characteristics of Indian almond (Prunus amygdalus). Nut. J. of Nutrition. 2011;4: 316-318.

30. Liu AM, Chang CU. Effect of soy milk characteristics and cooking conditions coagulant requirements for making filled tofu Department of Cereal and Food Sciences, North Dakota State University, Fargo, North Dakota 5810; 2004.

31. Soha $\mathrm{RH}$. The composition of milk in Fundamentals of Dairy Chemistry. Second edition, edited by Webb $\mathrm{BH}$.; Johnson $\mathrm{RH}$. Griffiths MW. 2012;104-108.

32. Nelson, Somogi LR. Chemical, physical and sensory characteristics of soy milk as affected by processing conditions. J. Food Science. 2000;57:401-405.

33. Donkor O, Henriksson A, Asiljevic TV, Shah NP. Galactosidase and proteolytic 
activities of selected probiotic and dairy cultures in fermented soymilk. Food Chemistry. 2007;104:10-20.

34. Salma HD. Major advances in fresh milk and milk products. Fluid milk products and frozen desserts. American Dairy Science. 2016;69:1163-1173. And Alford, J. A. The AVI Publishing Co. Inc. Westport connection, USA.

35. Abdullah A, Malundo TMM, Resurrection AVA, Beuchat LR. Descriptive sensory profiling for optimising the formula of a peanut milk-based-liquid coffee whitener. J. Food Sci. 1993;58(1):120-123. American Peanut Research and Education, Inc. Peanuts Culture and Uses. 1973;601.

36. Laswai HS, Thonya N, Yesaya D, Silayo VCK, Kalwa K, Mpagalile JJ, Ballegu WRN. Use of locally available flavouring materials in suppressing the beany taste in soy milk. Afri. J. Food Agric. Nutr. Dev. 2009;9(7):1548-1560.

37. Hayes MG, Fox PF, Kelly AL. Potential applications of high-pressure homogenization in processing of liquid milk. J. of Dairy Research. 2005;72:25-33.
38. Yau-Chun LV, Huan-Lu S, Xin L, Liang W, Shun-Tang G. Influence of blanching and grinding with hot water on beany and not beany flavour in soy milk. J. Food Sci. 2011;76(1):20-25.

39. Yuan S, Chang SK, Liu Z, Xu B. Elimination of trypsin inhibitor activity and beany flavour in soy milk by consecutive blanching and Ultra-High Temperature (UHT) processing. J. Agric. Food Chem. 2008;56(17):7957-7963.

40. Chiewchan N, Simuang J, Tansa kul A. Effects of fat content and temperature on the apparent viscosity of coconut milk. Journal of Food Engineering. 2004;64(2): 193-197.

41. Rehman S, Nawaz $H$, Ahmad MM, Hussain S, Murtaza A, Shahid SH. Physicochemical and sensory evaluation of ready to drink soy-cow milk blend. Pak. J. Nutr. 2007; 6(3):283285.

42. Onuorah CE, Adejare AO, Uhiara NS. Comparative physicochemical evaluation of soymilk and soya cake produced by three different methods. Nig. Food J. 2007;25:28-38.

(0) 2020 Siddeeg et al.; This is an Open Access article distributed under the terms of the Creative Commons Attribution License (http://creativecommons.org/licenses/by/4.0), which permits unrestricted use, distribution, and reproduction in any medium, provided the original work is properly cited.

Peer-review history:

The peer review history for this paper can be accessed here: http://www.sdiarticle4.com/review-history/59779 